\title{
Congenital Dysfibrinogenemia Presented with Massive Hematomas Formed after Hysterectomy
}

\author{
Kenji Niwa ${ }^{1}$, Kentaro Nagata1, Takefumi Nakagami' ${ }^{2}$, Ryuichiro Shimaoka ${ }^{3}$, Kentaro Niwa ${ }^{4}$, \\ Motoki Takenaka ${ }^{3}$, Takuji Tanaka ${ }^{5}$, Nobuo Okumura ${ }^{6}$ \\ ${ }^{1}$ Department of Obstetrics \& Gynecology, Gujo City Hospital, Gujo, Japan \\ ${ }^{2}$ Section of Laboratory Medicine and Obstetrics \& Gynecology, Gujo City Hospital, Gujo, Japan \\ ${ }^{3}$ Department of Obstetrics \& Gynecology, Gifu University School of Medicine, Gifu, Japan \\ ${ }^{4}$ Department of Obstetrics \& Gynecology, University of Fukui Hospital, Fukui Prefecture, Japan \\ ${ }^{5}$ Department of Diagnostic Pathology \& Research Center of Diagnostic Pathology, Gifu Municipal Hospital, Gifu, Japan \\ ${ }^{6}$ Department of Clinical Laboratory Sciences, School of Health Sciences, Shinshu University, Matsumoto, Japan \\ Email: *kniwa.gujo913@gmail.com
}

\begin{abstract}
How to cite this paper: Niwa, K., Nagata, K., Nakagami, T., Shimaoka, R., Niwa, K., Takenaka, M., Tanaka, T. and Okumura, N. (2021) Congenital Dysfibrinogenemia Presented with Massive Hematomas Formed after Hysterectomy. Case Reports in Clinical Medicine, 10, 108-116.

https://doi.org/10.4236/crcm.2021.104013
\end{abstract}

Received: March 19, 2021

Accepted: April 19, 2021

Published: April 22, 2021

Copyright $\odot 2021$ by author(s) and Scientific Research Publishing Inc. This work is licensed under the Creative Commons Attribution International License (CC BY 4.0).

http://creativecommons.org/licenses/by/4.0/

\begin{abstract}
Congenital dysfibrinogenemia (CD) is a qualitative congenital fibrinogen (Fbg) disorder characterized by normal antigen levels of dysfunctional Fbg. A 41-year-old Japanese woman visited the emergent room of our hospital due to acute and severe abdominal pain. Catheterization of the full bladder released her abdominal pain. Magnetic resonance imaging showed a huge pelvic mass, suggesting an intra-mural giant myoma. Before the removal operation of myoma, screening tests showed no abnormalities, including prothrombin time and activated partial thromboplastin time. However, Fbg level was not determined. The patient wanted to receive early surgical treatment, and an abdominal hysterectomy was performed as usual and the intra-operative blood loss was $100 \mathrm{~g}(\mathrm{ml})$. However, we found subcutaneous and pelvic hematomas, although active bleeding was not recognized on an emergent computed tomography examination. At that time, we noticed a low level of plasma $\mathrm{Fbg}(47 \mathrm{mg} / \mathrm{dl})$. We performed a re-laparotomy to remove hematomas. All ligated blood vessels were re-ligated, and oozing points were vaporized. Around the re-operation, six units of fresh frozen plasma and twelve units of red blood cell suspension were transfused. The clinical course after the $2^{\text {nd }}$ operation was uneventful except for the low level of Fbg. An additional study showed that the value of the Fbg activity and antigen was dissociated, and the patient was diagnosed CD with 7275 Arg to His (CGC to CAC) mutation.
\end{abstract}




\section{Keywords}

Dysfibrinogenemia, Asymptomatic, Major Bleeding Event, $\gamma 275$ Arg to His Mutation

\section{Introduction}

Congenital fibrinogen disorders comprise two classes of plasma fibrinogen (Fbg) defects: type I, afibrinogenemia or hypofibrinogenemia; and type II, dysfibrinogenemia or hypodysfibrinogenemia, in which there are normal or reduced antigen levels associated with disproportionately low functional activity (qualitative fibrinogen deficiencies) [1] [2]. The first patient of congenital dysfibrinogenemia (CD) was recognized in 1955 [3] and the point mutation was reported in Fbg Detroit I in 1968 [4]. Since then, more than 100 mutations and 400 families have been reported [1] [2]. About 20\% of fibrinogen gene mutations are known to be responsible for thrombosis [5].

Patients with CD might be identified during the clinical investigation of bleeding [6] or thrombosis [7], or following miscarriage [8]. However, most patients are asymptomatic and are usually discovered by the findings of prolongation of routine parameters of coagulation, such as prothrombin time (PT) and activated partial thromboplastin time (APTT) [9]. The majority of propositi of CD had an incidental diagnosis [10] [11]. CD is usually suspected if there is a discrepancy between clottable and immunologic fibrinogen levels.

We report here an asymptomatic CD case with $\gamma 275$ Arg to His (CGC to CAC) mutation, presented with massive hematomas formed soon after an abdominal hysterectomy,

\section{Case Report}

A 41-year-old Japanese woman, virgin and single, visited the emergent room at Gujo City Hospital due to acute and unbearable abdominal pain. An emergent computed tomography (CT) examination showed full bladder distension due to a giant myoma of the uterus. Catheterization of the bladder released her abdominal pain. Then, she was introduced to the Department of Obstetrics and Gynecology. She had a normal menstrual cycle without hyper- and dysmenorrhea, and had no history of hemorrhagic diathesis and thrombus. magnetic resonance imaging (MRI) showed a huge pelvic mass, suggesting an intra-mural giant myoma in her backside, apart from the endometrium (Figure 1(A)). Screening tests before the operation showed no abnormalities, including PT and APTT (Table 1) and liver functions. She wished to receive an early hysterectomy, and then she underwent an abdominal hysterectomy and bilateral salpingectomy (Figure 1(B)) for reducing the future ovarian cancer incidence [12], after administering $\mathrm{GnRH}$ antagonist for one month. The operation for 121 minutes was performed as usual, and the blood loss was $100 \mathrm{~g}(\mathrm{ml})$. The patient showed an uneventful course for approximately six hours after the end of operation, but 
Table 1. Summary of coagulation test results.

\begin{tabular}{|c|c|c|c|c|c|c|c|c|c|}
\hline \multirow{2}{*}{$\begin{array}{c}\text { Parameter } \\
\text { (reference values) }\end{array}$} & \multirow{2}{*}{$\begin{array}{c}\text { Pre- } \\
\text { operation }\end{array}$} & \multicolumn{3}{|c|}{ Re-operation } & \multicolumn{5}{|c|}{ Day and week after Re-operation } \\
\hline & & Before & $3 \mathrm{hrs}$. after & 8 hrs. after & Day 1 & Day 3 & Day 5 & Week 2 & Week 6 \\
\hline $\begin{array}{c}\text { PT } \\
(80 \%-120 \%)\end{array}$ & 96.9 & 80.9 & 91.7 & - & 96.9 & - & - & 95.1 & 86.4 \\
\hline $\begin{array}{c}\text { APTT } \\
(23-38 \mathrm{sec})\end{array}$ & 31.2 & 28 & 28.1 & - & 31.8 & - & - & 31.4 & 36.4 \\
\hline $\begin{array}{l}\text { Active Fibrinogen } \\
(180-350 \mathrm{mg} / \mathrm{dl})\end{array}$ & - & 47 & 76 & 113 & 116 & 122 & 111 & 64 & 61 \\
\hline $\begin{array}{l}\text { Fibrinogen antigen } \\
(180-350 \mathrm{mg} / \mathrm{dl})\end{array}$ & - & - & & & - & - & - & - & 159 \\
\hline
\end{tabular}
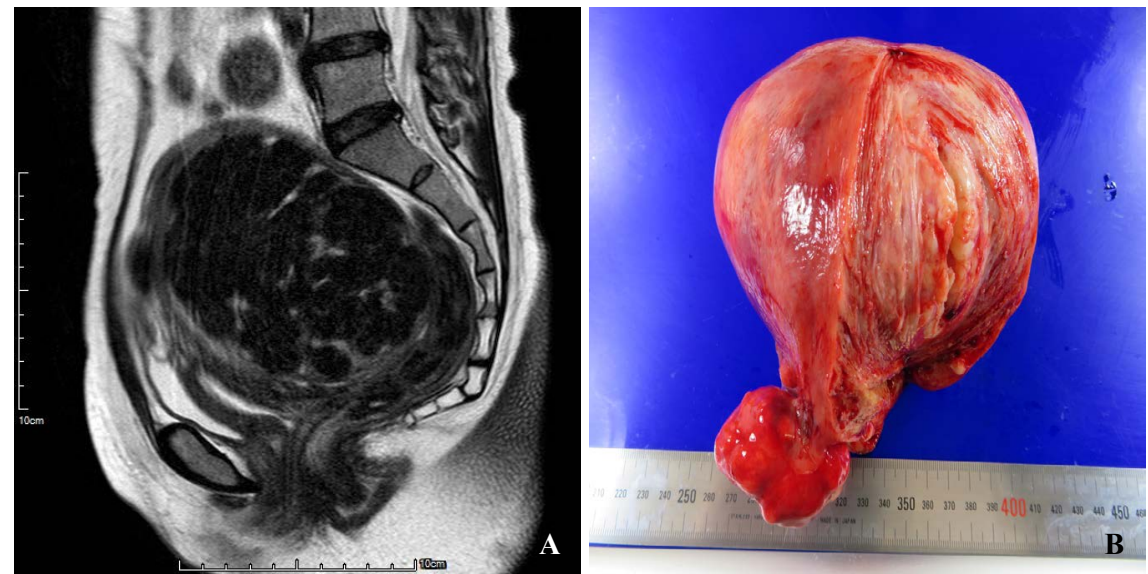

Figure 1. (A) A huge mass, approximately $12 \mathrm{~cm}$ in diameter, suggesting leiomyoma, presented at the backside (T2-weighted magnetic resonance imaging). (B) The resected uterus had a huge mass.

then she showed abdominal distension with tachycardia and hypotension, suggesting massive bleeding. Emergent $\mathrm{CT}$ and laboratory examinations revealed two massive hematomas in the abdominal subcutaneous fat tissue and muscle area (Figure 2) and the pelvic bottom. The laboratory examination before the re-operation showed a low level of plasma Fbg (47 mg/dl), as listed in Table 1. After then, we decided to perform a re-laparotomy after preparation of fresh frozen plasma (FFP) and red blood cell (RBC) suspension. At the re-laparotomy, one bigger hematoma under the abdominal muscle fascia and the other smaller on the pelvic floor after hysterectomy was present, but apparent bleeding points could not be detected. Hematomas were removed, and all ligated blood vessels were re-ligated. Some oozing points were vaporized by the electrocision. The blood loss including hematomas was $801 \mathrm{~g}(\mathrm{ml})$. Six units of FFP and twelve units of RBC suspension were transfused before and after the re-operation. After the $2^{\text {nd }}$ operation, the clinical course was uneventfully excepted with low level of Fbg activity (Table 1 ). The post-operative course of the $2^{\text {nd }}$ operation was uneventful and the patient was discharged on $6^{\text {th }}$ day after the $2^{\text {nd }}$ operation. Pathological examination of a giant uterine tumor revealed leiomyoma (Figure 3), and two weeks after the operation, the Fbg activity showed still the low level 
(Table 1). After then, we decided to determine the differential diagnosis of low or dysfibrinogenemia; therefore consulted Prof. Okumura, Shinshu University, who is an expert of $\mathrm{CD}$ and one of the co-authors. As the value of the Fbg activity and antigen was dissociated (Table 1), dysfibrinogenemia rather than hypofibrinogenemia was considered [13]. Thus, we analyzed the mutation(s) of fibrinogen genes, $F G A, F G B$ and $F G G$ [14]. Genetic analysis was approved by the Ethical Review Board of Shinshu University School of Medicine (\#603) and after informed consent had been obtained from the patient, blood samples were collected. Polymerase chain reaction-amplification of the Fbg gene was performed and direct DNA sequencing was done as described in a previous report [12]. A G to A substitution resulted in the replacement of wild-type Arg at residue 275 by His (Figure 4) [14]. The patient was diagnosed CD with $\gamma 275$ Arg to His (CGC to $\mathrm{CAC})$.

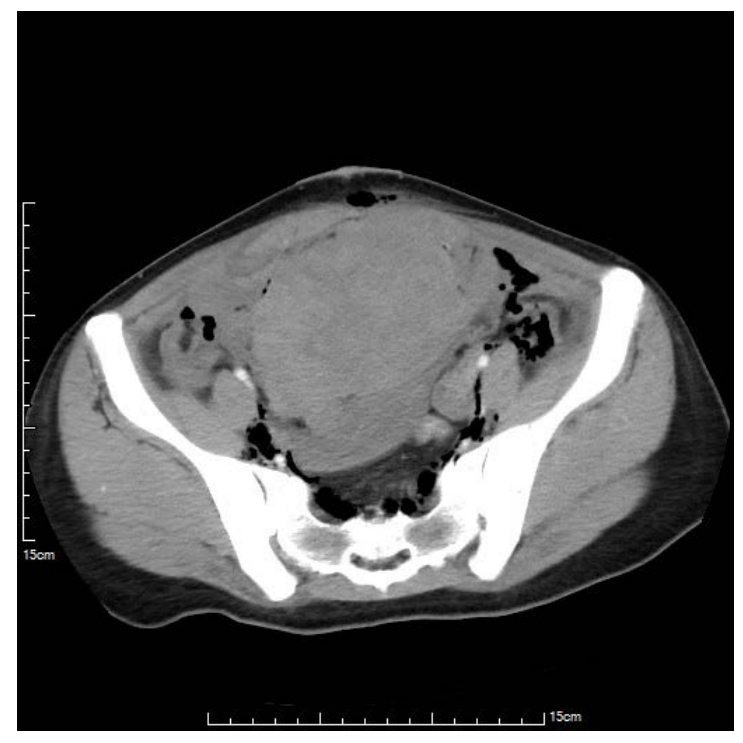

Figure 2. A big hematoma, measuring approximate $11 \mathrm{~cm}$ was seen subcutaneously, and the other was also found in the pelvic bottom (not seen). Active bleeding could not be found on enhanced CT.

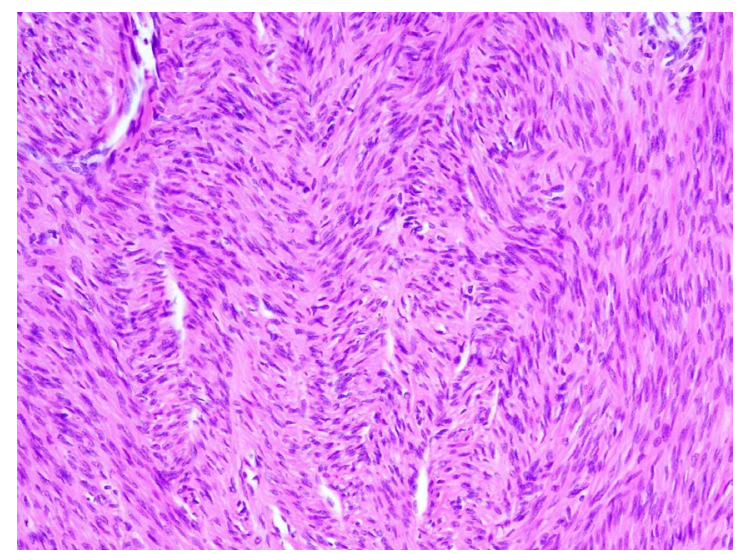

Figure 3. Histopathology of a huge mass shows leiomyoma composed of spindle cell tumor cells. Hematoxylin \& eosin stain, magnification $\times 100$. 


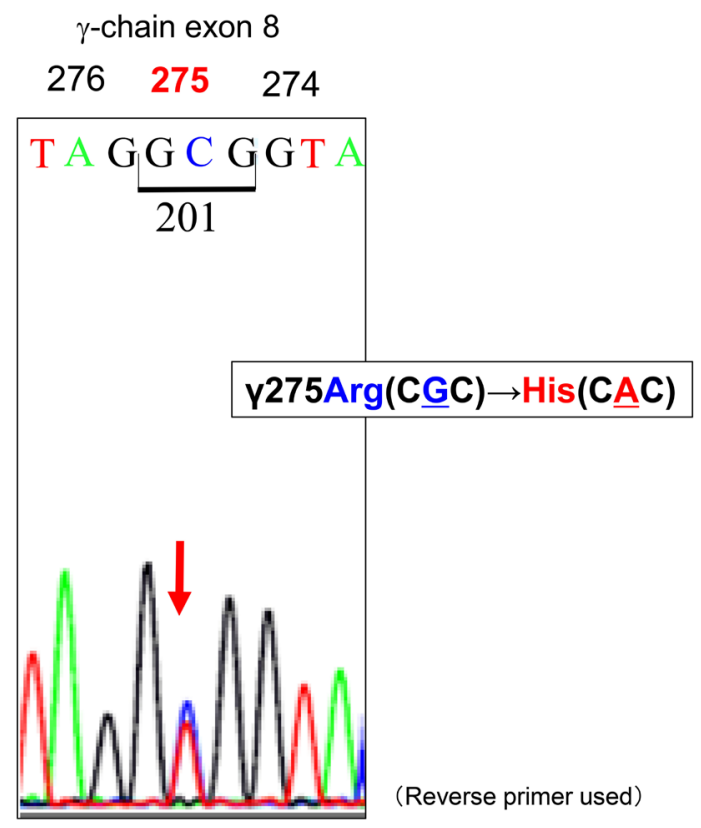

Figure 4. Nucleotide sequences of $F G G$ exon 8 . The PCR-amplified gene was sequenced using a reverse primer. A GCG was transited to GTG used reserved primers, meaning $2275 \mathrm{Arg}$ (CGC) was transited to His (CAC) used forward primers.

After nine months of the $2^{\text {nd }}$ surgery, the patient is healthily without hemorrhage and thrombosis episodes. After diagnosing the patient, we interviewed her family medical history, including hemorrhage or thrombosis episodes, and commissioned to examine the level of Fbg activity of her family in another hospital. Her father and brother were confirmed to be the low level of Fbg activity, but they had no episodes of hemorrhage or thrombosis. The mutations of fibrinogen gene of this patient's father and brother have not been examined.

\section{Discussion}

The present patient remained asymptomatic until the hematomas formed after the $1^{\text {st }}$ operation. An accidental injury of the venule might occur because of a little blood loss $[100 \mathrm{~g}(\mathrm{ml})]$ of the $1^{\text {st }}$ operation. After forming subcutaneous hematoma, the Fbg might be consumed and the second hematoma might form in the abdominal cavity/pelvic bottom. Most gynecological manifestations of $\mathrm{CD}$ cases [10], even presently are thought to be menorrhagia, spontaneous recurrent abortion, antepartum and postpartum hemorrhage [13]. However, this patient had no bleeding episode, including menorrhagia, spontaneous recurrent abortion, and antepartum/postpartum hemorrhage, as she did not experience pregnancy.

Determining intraperitoneal hemorrhage and its causes by diagnostic imaging including abdominal ultrasonography, CT and MRI are thought to be critical to treatment planning. Especially, enhanced CT might be the best tool for determining active bleeding [15]. In the present case, two large hematomas, but no 
active bleeding, were observed on an emergent CT.

In general, Fbg is an abundant protein synthesized in the liver, present in human blood plasma at concentrations ranging $180-350 \mathrm{mg} / \mathrm{dl}$ in healthy individuals with a normal half-life of 3 - 5 days [16]. Before the $2^{\text {nd }}$ operation, we found that the Fbg (activity) was low level [47 (mg/dl)]. The patient showed the low level of Fbg up to 6 months after the operation. After the preparation of FFP, we removed the hematomas and do stanching operations. The differential diagnosis of low and dysfibrinogenemia should be done. In this case, as the value of the Fbg activity and antigen was dissociated, we considered dysfibrinogenemia rather than hypofibrinogenemia [13].

For the definitive diagnosis, a $\mathrm{G}$ to A substitution resulted in the replacement of wild-type Arg at residue 275 by His [14]. The patient was diagnosed CD with $\gamma 275$ Arg to His (CGC to CAC). CD is generally associated with autosomal dominant inheritance caused by heterozygosity for missense mutations [13]. The most frequent mutations are substitutions in the $\mathrm{N}$-terminal region of $\mathrm{A} \alpha$ chain or in the C-terminal region of the $\gamma$ chain that result in defective interaction between the two terminal $\mathrm{D}$ regions and the $\mathrm{E}$ region, or in defective $\mathrm{D}: \mathrm{D}$ interactions, thus causing a defect in the assembly of fibrin in early clot formation [17]. Mutations in exon 2 of $F G A$ and exon 8 of $F G G$ account for almost $85 \%$ of all CD mutations [13]. The present case showed $\gamma 275$ Arg to His mutation in exon 8 of $F G G$. Several reports described same mutation in the CD patients [9] [18] [19] [20]. The R275 residue is known to be the most commonly mutated site in the globular carboxyl-terminal region of the $\gamma$-chain [21]. Usually, affected individuals do not show thrombo-embolic complications. However, thrombotic complications were reported in three of the nine families with heterozygous mutations encoding Arg275 $\rightarrow$ His substitutions [18]. While no bleeding or thrombotic events have occurred in the patient's family, it is possible that thrombotic or hemorrhagic events may occur in the future, especially in the case of surgery, delivery, or trauma [22]. Therefore, the patient and her family still need follow-up to prevent thrombosis, bleeding, or other related events.

As for CDs, bleeding is generally mild, and also PT and APTT tests in most cases showed normal range, as shown in this case [9]. As the pre-operative screening test for suspicious for massive hemorrhage during operation, Fbg must be included especially in CD's relatives living areas. When suspected for CD who will receive operation for cardiovascular and/or major bleeding, FFP or cryoprecipitate should be prepared before the operation [13].

\section{Conclusion}

$\mathrm{CD}$ is a qualitative Fbg disorder characterized by normal antigen levels of a dysfunctional Fbg. We presented a 41-year-old Japanese woman who received an abdominal hysterectomy as usual, but hematomas formed after the operation. The dissociated values of Fbg activity and antigen suggested dysfibrinogenemia and genetic analysis revealed CD with $\gamma 275$ Arg to His (CGC to CAC) mutation. 


\section{Consent}

Verbal consent was obtained from the patient before writing this case report.

\section{Ethical Approval}

This was obtained from the ethical committee of our hospital before writing this case report.

\section{Acknowledgements}

We thank the editor and reviewers for the constructive comments, which helped us to improve the manuscript. This case report was approved by the patient verbal consent.

\section{Conflicts of Interest}

The authors declare no conflicts of interest regarding the publication of this paper.

\section{References}

[1] de Moerloose, P., Casini, A. and Neerman-Arbez, M. (2013) Congenital Fibrinogen Disorders: An Update. Seminars in Thrombosis and Hemostasis, 39, 585-595. https://doi.org/10.1055/s-0033-1349222

[2] Neerman-Arbez, M. and Casini, A. (2018) Clinical Consequences and Molecular Bases of Low Fibrinogen Levels. International Journal of Molecular Sciences, 19, 192. https://doi.org/10.3390/ijms19010192

[3] Ingram, G.I. (1955) Variations in the Reaction between Thrombin and Fibrinogen and Their Effect on the Prothrombin Time. Journal of Clinical Pathology, 8, 318-323. https://doi.org/10.1136/jcp.8.4.318

[4] Blomback, M., Blomback, B., Mammen, E.F. and Prasad, A.S. (1968) Fibrinogen Detroit-A Molecular Defect in the N-Terminal Disulphide Knot of Human Fibrinogen? Nature, 218, 134-137. https://doi.org/10.1038/218134a0

[5] Yoshida, S., Kibe, T., Matsubara, R., Koizumi, S.I., Nara, K., Amano, K. and Okumura, N. (2017) Congenital Dysfibrinogenemia in a Japanese Family with Fibrinogen Naples (BßAla68Thr) Manifesting as Superior Sagittal Sinus Thrombosis. Blood Coagulation and Fibrinolysis, 28, 580-584. https://doi.org/10.1097/MBC.0000000000000641

[6] Brennan, S.O., Mosesson, M.W., Lowen, R. and Frantz, C. (2006) Dysfibrinogenemia (Fibrinogen Wilmington) Due to a Novel Aa Chain Truncation Causing Decreased Plasma Expression and Impaired Fibrin Polymerization. Thrombosis and Haemostasis, 96, 88-89. https://doi.org/10.1160/TH05-11-0749

[7] de Raucourt, E., Fischer, A.M., Meyer, G. and de Mazancourt, P. (2006) A B $\beta 14$ Arg $\rightarrow$ Cys Fibrinogen Variant in a Patient with Thrombotic Complications (Fibrinogen St-Germain III). Journal of Thrombosis and Haemostasis, 4, 2722-2723. https://doi.org/10.1111/j.1538-7836.2006.02240.x

[8] Dempfle, C.E., George, P.M., Borggrefe, M., Neumaier, M. and Brennan, S.O. (2009) Demonstration of Heterodimeric Fibrinogen Molecules Partially Conjugated with Albumin in a Novel Dysfibrinogen: Fibrinogen Mannheim V. Thrombosis and Haemostasis, 102, 29-34. https://doi.org/10.1160/TH08-09-0559 
[9] Cunningham, M.T., Brandt, J.T., Laposata, M. and Olson, J.D. (2002) Laboratory Diagnosis of Dysfibrinogenemia. Archives of Pathology \& Laboratory Medicine, 126, 499-505. https://doi.org/10.5858/2002-126-0499-LDOD

[10] Casini, A., Blondon, M., Lebreton, A., Koegel, J., Tintillier, V., de Maistre, E., Gautier, P., Biron, C., Neerman-Arbez, M. and de Moerloose, P. (2015) Natural History of Patients with Congenital Dysfibrinogenemia. Blood, 125, 553-561. https://doi.org/10.1182/blood-2014-06-582866

[11] Casini, A., Neerman-Arbez, M., Ariens, R.A. and de Moerloose, P. (2015) Dysfibrinogenemia: From Molecular Anomalies to Clinical Manifestations and Management. Journal of Thrombosis and Haemostasis, 13, 909-919. https://doi.org/10.1111/jth.12916

[12] Anggraeni, T.D., Al Fattah, A.N. and Surya, R. (2018) Prophylactic Salpingectomy and Ovarian Cancer: An Evidence-Based Analysis. South Asian Journal of Cancer, 7, 42-45. https://doi.org/10.4103/sajc.sajc_187_17

[13] Yoda, M., Kaido, T., Taira, C., Higuchi, Y., Arai, S. and Okumura, N. (2020) Congenital Fibrinogen Disorder with a Compound Heterozygote Possessing Two Novel FGB Mutations, One Qualitative and the Other Quantitative. Thrombosis Research, 196, 152-158. https://doi.org/10.1016/j.thromres.2020.08.031

[14] Terasawa, F., Okumura, N., Higuchi, Y., Ishikawa, S., Tozuka, M., Ishida, F., Kitano, K. and Katsuyama, T. (1999) Fibrinogen Matsumoto III: A Variant with Г275 Arg $\rightarrow$ Cys $(C G C \rightarrow$ TGC) - Comparison of Fibrin Polymerization Properties with Those of Matsumoto I (Г364 Asp $\rightarrow$ His) and Matsumoto II (Г308 Asn $\rightarrow$ Lys). Thrombosis and Haemostasis, 81, 763-766. https://doi.org/10.1055/s-0037-1614568

[15] Willmann, J.K., Roos, J.E., Platz, A., Pfammatter, T., Hilfiker, P.R., Marincek, B. and Weishaupt, D. (2002) Multidetector CT: Detection of Active Hemorrhage in $\mathrm{Pa}$ tients with Blunt Abdominal Trauma. AJR American Journal of Roentgenology, 179, 437-444. https://doi.org/10.2214/ajr.179.2.1790437

[16] Vilar, R., Fish, R.J., Casini, A. and Neerman-Arbez, M. (2020) Fibrin (Ogen) in Human Disease: Both Friend and Foe. Haematologica, 105, 284-296. https://doi.org/10.3324/haematol.2019.236901

[17] N.-A., M. and de Moerloose, P. (2010) Hereditary Fibrinogen Abnormalities. In: Kaushansky, K., Lichtman, M., Beutler, E., Kipps, T., Prchanl, J. and Seigsohn, U., Eds., Williams Hematology, McGraw-Hill, New York, 1-33.

[18] Linenberger, M.L., Kindelan, J., Bennett, R.L., Reiner, A.P. and Cote, H.C. (2000) Fibrinogen Bellingham: A $\Gamma$-Chain R275C Substitution and a B-Promoter Polymorphism in a Thrombotic Member of an Asymptomatic Family. American Journal of Hematology, 64, 242-250. https://doi.org/10.1002/1096-8652(200008)64:4<242::AID-AJH2>3.0.CO;2-O

[19] Yamazumi, K., Terukina, S., Onohara, S. and Matsuda, M. (1988) Normal Plasmic Cleavage of the $\Gamma$-Chain Variant of "Fibrinogen Saga" with an Arg-275 to His Substitution. Thrombosis and Haemostasis, 60, 476-480.

https://doi.org/10.1055/s-0038-1646994

[20] Terukina, S., Matsuda, M., Hirata, H., Takeda, Y., Miyata, T., Takao, T. and Shimonishi, Y. (1988) Substitution of ГArg-275 by Cys in an Abnormal Fibrinogen, "Fibrinogen Osaka II". Evidence for a Unique Solitary Cystine Structure at the Mutation Site. Journal of Biological Chemistry, 263, 13579-13587. https://doi.org/10.1016/S0021-9258(18)68281-X

[21] Cote, H.C., Lord, S.T. and Pratt, K.P. (1998) Г-Chain Dysfibrinogenemias: Molecular Structure-Function Relationships of Naturally Occurring Mutations in the $\Gamma$ 
Chain of Human Fibrinogen. Blood, 92, 2195-2212.

[22] Alving, B.M. and Henschen, A.H. (1987) Fibrinogen Giessen I: A Congenital Homozygously Expressed Dysfibrinogenemia with Aa 16 Arg $\leftarrow$ His Substitution. American Journal of Hematology, 25, 479-482.

https://doi.org/10.1002/ajh.2830250414 